\title{
Enamel Hypoplasia in Relation to Caries in Guatemalan Children
}

\author{
Peter F. Infante* and George M. Gillespie \\ Center for Human Growth and Development, University of Michigan, Ann Arbor, Michigan \\ 48109, USA, and Dental Section, Pan American Health Organization, Washington, DC, USA
}

Guatemalan children with anterior linear enamel hypoplasia (LEH) had a significantly greater caries experience in posterior dentition than their peers who did not have anterior LEH. The findings suggest that the synergistic mechanism of undernutrition and infection, which may underlie the occurrence of anterior LEH, may also predispose clinically normal appearing deciduous molars to an excessive caries attack equal to that observed in the grossly hypoplastic anterior teeth. The nutritional implications merit further investigation.

Linear enamel hypoplasia (LEH) of the deciduous maxillary incisors is commonly observed in undernourished children throughout the world. ${ }^{1-4}$ The lesion is very rarely observed in the posterior dentition. Clinically, the lesion is characterized by a horizontal groove most frequently found on the labial surface of the middle third of the maxillary central incisors and on the incisal third of the maxillary lateral incisors. Although the etiology of this enamel defect is undetermined, factors associated with the synergistic mechanisms of undernutrition and infection ${ }^{5,6}$ common to populations where the lesion is prevalent may be contributing factors. ${ }^{7-9}$ In children living in communities where caries prevalence is relatively high, the eruption of these defective teeth into the oral cavity is usually followed by a highly invasive caries attack. The teeth often become reduced to blackened stumps and chronic periapical abscess follows. ${ }^{3,4,8}$ Since a high caries attack in the posterior dentition of Apache Indian children with anterior LEH had been obviously previously ${ }^{10}$ and Russell ${ }^{11}$ and Russell

Received for publication April 21, 1975.

Accepted for publication June 11, 1976

* Present address: Biometry Section, Division of Surveillance, Hazard Evaluations and Field Studies, National Institute for Occupational Safety and Health, Cincinnati, Ohio 45202. et al $^{12}$ had observed entire crowns of deciduous molars destroyed proximate to cariesfree first permanent molars in children of other malnourished populations, the data presented here were analyzed to determine the relation of anterior LEH to caries experience in the deciduous molars of Guatemalan children two through seven years of age.

\section{Materials and Methods}

Using field methodology for caries detection as described previously, ${ }^{13}$ oral examinations were conducted in four rural Guatemalan Ladino villages located in the Department of El Progreso. Anterior teeth were scrubbed with a gauze sponge to facilitate detection of the lesions. All dental examinations were conducted by one examiner. Calibration procedures for caries and enamel hypoplasia classification were conducted before the field portion of the study. For enamel hypoplasia status, children were categorized as reported previously. ${ }^{7}$ For the first analysis, children categorized as questionable as to whether they had LEH were combined with children identified as not having $\mathrm{LEH}$, and children in whom LEH was not possible to determine were combined. Thus, three groups remained for analysis: 113 children with LEH, 246 without $\mathrm{LEH}$, and 29 in whom LEH was not possible to determine because caries was either too extensive or because the maxillary incisors had been exfoliated. Since LEH obviously contributed to the high caries attack rate in the anterior teetn of these children, it was decided to determine the extent to which caries experience in the posterior teeth (teeth that rarely manifest LEH) might be related to the presence or absence of LEH in the anterior teeth. Thus, mean numbers of decayed deciduous molar teeth and tooth surfaces as well as percentages of children in whom all eight deciduous molars 
TABLE 1

Mean Total Numbers of Garious Deciduous Molar Teeth and Surfages in Children by Linear Hypoplasia Status and Age, Boys and Grrls Combined,

Guatemala, 1973

\begin{tabular}{|c|c|c|c|c|c|c|c|c|c|}
\hline \multirow{3}{*}{$\begin{array}{l}\text { Age } \\
\text { Group } \\
\text { (Yr) }\end{array}$} & \multicolumn{3}{|c|}{$\begin{array}{c}\text { Children With } \\
\text { Anterior Hypoplasia }\end{array}$} & \multicolumn{3}{|c|}{$\begin{array}{l}\text { Children Without } \\
\text { Anterior Hypoplasia }\end{array}$} & \multicolumn{3}{|c|}{$\begin{array}{l}\text { N.P.D.* Because of } \\
\text { Caries or Exfoliation }\end{array}$} \\
\hline & \multicolumn{3}{|c|}{ Mean Decayed Molars } & \multicolumn{3}{|c|}{ Mean Decayed Molars } & \multicolumn{3}{|c|}{ Mean Decayed Molars } \\
\hline & $\mathbf{N}$ & (Teeth) & (Surfaces) & $\mathrm{N}$ & (Teeth) & (Surfaces) & $\mathrm{N}$ & (Teeth) & (Surfaces) \\
\hline 2 & 33 & 1.03 & 1.33 & 53 & 0.28 & 0.36 & 0 & - & - \\
\hline 3 & 16 & 2.88 & 3.88 & 65 & 1.06 & 1.29 & 7 & 5.29 & 8.14 \\
\hline 4 & 24 & 3.88 & 5.75 & 42 & 1.69 & 2.12 & 8 & 5.00 & 9.25 \\
\hline 5 & 19 & 5.74 & 12.32 & 48 & 2.15 & 3.08 & 4 & 4.25 & 6.75 \\
\hline 6 & 21 & 5.05 & 10.67 & 38 & 3.16 & 5.53 & 10 & 6.50 & 12.50 \\
\hline
\end{tabular}

* N.P.D., Not possible to determine linear hypoplasia status.

were cariesfree were computed for children with versus those without anterior LEH.

\section{Results}

As given in Table 1, children with anterior LEH had mean numbers of decayed deciduous molar teeth and tooth surfaces that were about two to four times greater than the means in children without anterior LEH. The percentages of children with one or more decayed deciduous molars were then computed for children positively identified as having anterior LEH and for children of all other categories combined. These data are given in Table 2. For each one-year age group comparison, the percentages of children in whom all of the deciduous molars were cariesfree were consistently lower in the group with anterior LEH versus all other children. With all age groups combined, $31 \%$ of the children with anterior LEH had one or more decayed deciduous molars as compared with $48 \%$ in the group of all other children. These differences were highly significant $(P<0.01)$ by Chi-square testing $\left(x^{2}=9.48 ; d f=1\right)$. If the 25 children with extensive decay of the maxillary incisors had not been included with "all other children," the differences would have been much greater.

The caries experience in these preschool Guatemalan children was previously reported to be about twice that reported for US white children. ${ }^{13}$ A large portion of this increased rate of caries attack was attributed to a greater involvement of caries in the hypoplastic areas of the anterior teeth. However, it was decided to estimate the contribution of factors associated with anterior LEH that might be related to caries involvement in the posterior teeth.

TABLE 2

Percentage of Children with Cariesfree Deciduous Molars by Anterior Linear Hypoplasia Status and Age, Boys and Girls Gombined, Guatemala, 1973

\begin{tabular}{|c|c|c|c|c|c|c|}
\hline \multirow[b]{2}{*}{$\begin{array}{l}\text { Age } \\
\text { Group }\end{array}$} & \multicolumn{3}{|c|}{$\begin{array}{c}\text { Children With Anterior } \\
\text { Linear Hypoplasia }\end{array}$} & \multicolumn{3}{|c|}{ All Other Children* } \\
\hline & $N$ & $\begin{array}{c}\text { Number With } \\
\text { Cariesfree } \\
\text { Molars }\end{array}$ & $\begin{array}{l}\text { Percent } \\
\text { Cariesfree }\end{array}$ & $\mathbf{N}$ & $\begin{array}{l}\text { Imber With } \\
\text { Cariesfree } \\
\text { Molars }\end{array}$ & $\begin{array}{l}\text { Percent } \\
\text { Cariesfree }\end{array}$ \\
\hline 2 & 33 & 24 & 72.7 & 53 & 44 & 83.0 \\
\hline 3 & 16 & 4 & 25.0 & 72 & 40 & 55.6 \\
\hline 4 & 24 & 5 & 20.8 & 50 & 15 & 30.0 \\
\hline 5 & 19 & 1 & 5.3 & 52 & 21 & 40.4 \\
\hline 6 & 21 & 1 & 4.8 & 48 & 12 & 25.0 \\
\hline All Ages & 113 & 35 & 31.0 & 275 & 132 & 48.0 \\
\hline
\end{tabular}

* All other children includes those positively identified as not having hypoplasia, plus 29 children in whom hypoplasia could not be determiend because of excessive crown destruction or exfoliation. 


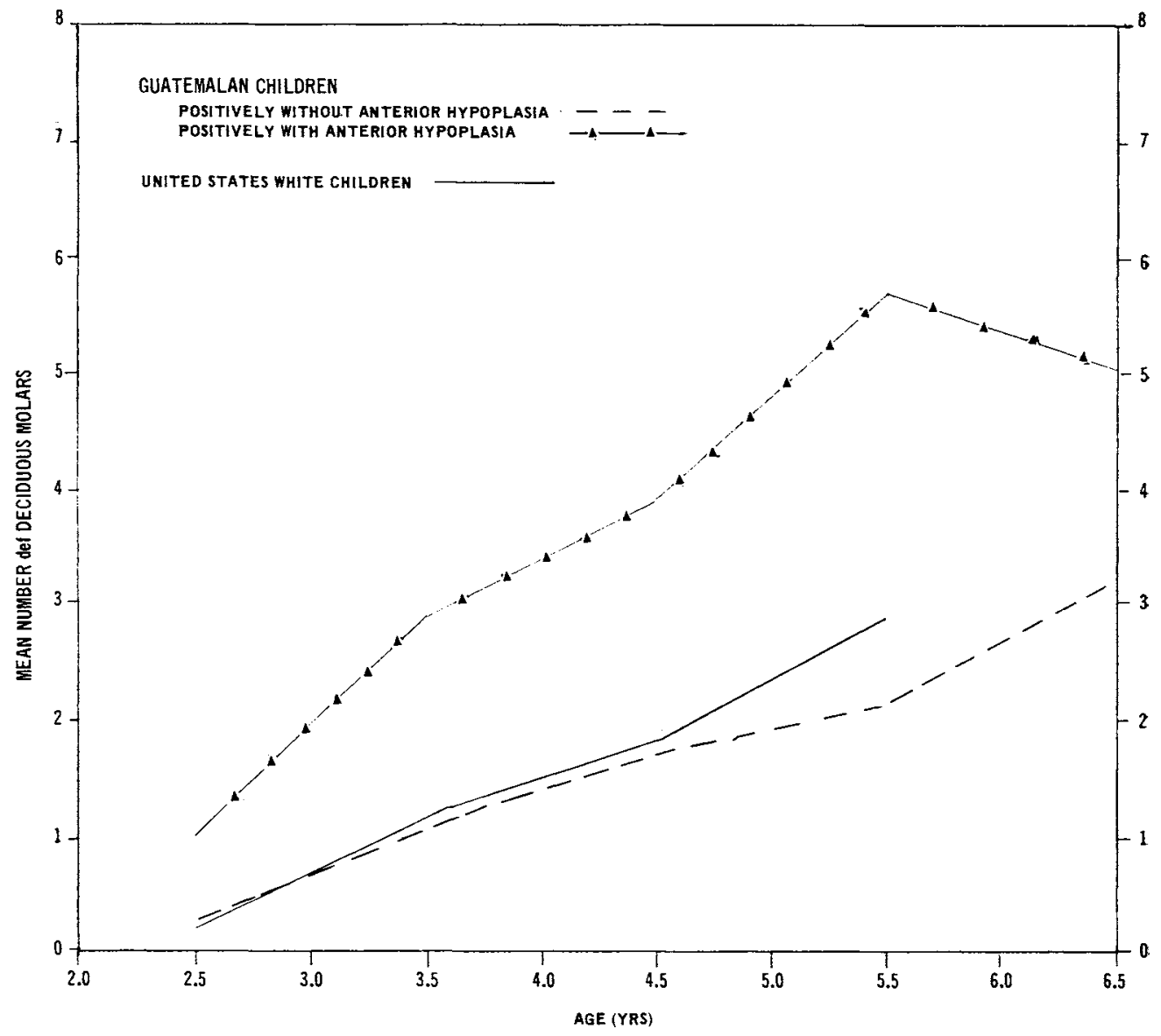

Fig-Mean number of decayed deciduous molar teeth in Guatamalan children with and without anterior LEH, 1973, and in the US white children, 1969-1970.

Thus, means for decayed molar teeth and tooth surfaces in the Guatemalan children were compared with similar data for US white children who were examined during the $\mathrm{Na}$ tional Preschool Nutritional Survey of 19691970. Children in both countries were examined by the same dentist, who used similar criteria for assessment of def molar teeth. Data for caries experience in the deciduous molars of Guatemalan children without anterior LEH and for US children are given in Table 3. Similar data for Guatemalan children positively identified with anterior LEH are given in Table 1. All of these data are shown graphically in the illustration. The illustration shows that the Guatemalan children with anterior LEH had about twice the mean number of decayed deciduous molars compared with their peers without hypoplasia and also compared to
US white children. Guatemalan children without LEH experienced caries in the deciduous molars similar to US white children. The findings given in Table 3 show that the age-standardized number of decayed deciduous molar teeth in the US children was 1.52 versus 1.43 in the Guatemalan children.

Since significant differences in the total number of deft by sex in the entire study population were observed as reported previously, ${ }^{13}$ data were analyzed by sex for children with and without anterior LEH. In children without anterior LEH, caries experience in the deciduous molars was virtually identical in both sexes. In the anterior teeth, however, boys had an average of about 0.4 and 0.6 additional decayed teeth and tooth surfaces, respectively. These data are given in Table 4.

In children with $\mathrm{LEH}$, with data for all 
TABLE 3

Mean Numbers of Degayed Degiduous Molars in Guatemalan Children without Anterior Linear Enamel Hypoplasia as Compared to United States White Children*

\begin{tabular}{|c|c|c|c|c|c|c|}
\hline \multirow[b]{2}{*}{$\begin{array}{l}\text { Age } \\
\text { Group } \\
\text { (Yrs) }\end{array}$} & \multicolumn{3}{|c|}{$\begin{array}{l}\text { Guatemalan Children } \\
\text { Without Hypoplasia }\end{array}$} & \multicolumn{3}{|c|}{ U.S. White Children } \\
\hline & $\begin{array}{c}\text { Mean } \\
\text { Age }\end{array}$ & $\mathrm{N}$ & $\begin{array}{c}\text { Mean Decayed } \\
\text { Deciduous Molars } \\
\text { (Teeth) }\end{array}$ & $\begin{array}{c}\text { Mean } \\
\text { Age }\end{array}$ & $\mathrm{N}$ & $\begin{array}{c}\text { Mean Decayed } \\
\text { Deciduous Molars } \\
\text { (Teeth) }\end{array}$ \\
\hline 2 & 2.52 & 53 & 0.28 & 2.50 & 186 & 0.18 \\
\hline 3 & 3.46 & 65 & 1.06 & 3.54 & 200 & 1.15 \\
\hline 4 & 4.48 & 42 & 1.69 & 4.52 & 207 & 1.81 \\
\hline 5 & 5.54 & 48 & 2.15 & 5.48 & 205 & 2.88 \\
\hline 6 & 6.43 & 38 & 3.16 & - & - & - \\
\hline All Ages & 4.30 & 246 & 1.54 & 4.05 & 798 & 1.54 \\
\hline Age-Std. & 4.00 & 246 & 1.43 & 4.00 & 798 & 1.52 \\
\hline
\end{tabular}

Age-Std., Age standardized to 4.00 years.

* Data source for US white children, National Preschool Nutritional Survey, 1969-70.

ages combined, boys had an average of 0.8 and 2.0 additional decayed molar teeth and tooth surfaces, respectively. These data are given in Table 5. Boys also had an average of 0.6 and 1.0 additional decayed anterior teeth and tooth surfaces, respectively. Thus, for comparisons by sex in children with $\mathrm{LEH}$, boys had a slightly greater caries attack in both the anterior and posterior teeth. In children without LEH, boys had a slightly greater caries attack in the anterior teeth only.
As given at the bottom of Table 5, children with anterior LEH had a mean of 2.95 and 3.43 anterior and posterior decayed teeth, respectively. Children without $\mathrm{LEH}$ (Table 4) had means of 1.26 and 1.54 for similar teeth. Thus, children with anterior LEH experienced 2.34 and 2.23 times greater caries attack in anterior and posterior teeth, respectively. These findings suggest that children with anterior LEH may have an increased caries susceptibility in the posterior teeth equal to that experi-

TABLE 4

Mean Numbers of Decayed Degiduous Anterior and Posterior Teeth and Tooth Surfaces in Children without Anterior Hypoplasia by SeX, Guatamala, 1973

\begin{tabular}{|c|c|c|c|c|c|c|}
\hline \multirow{2}{*}{$\begin{array}{l}\text { Age } \\
\text { Group } \\
\text { (Yrs) }\end{array}$} & \multirow[b]{2}{*}{$\begin{array}{c}\text { Mean } \\
\text { Age }\end{array}$} & \multirow[b]{2}{*}{$\mathbf{N}$} & \multicolumn{2}{|c|}{ Anterior Segment } & \multicolumn{2}{|c|}{ Posterior Segment } \\
\hline & & & $\begin{array}{r}\text { Mean } \\
\text { deft }\end{array}$ & $\begin{array}{c}\text { Mean } \\
\text { defs }\end{array}$ & $\begin{array}{c}\text { Mean } \\
\text { deft }\end{array}$ & $\begin{array}{c}\text { Mean } \\
\text { defs }\end{array}$ \\
\hline \multicolumn{7}{|c|}{ BOYS } \\
\hline 2 & 2.50 & 25 & 0.52 & 0.72 & 0.24 & 0.32 \\
\hline 3 & 3.48 & 29 & 1.10 & 1.31 & 1.10 & 1.21 \\
\hline 4 & 4.53 & 26 & 1.58 & 2.00 & 1.50 & 1.92 \\
\hline 5 & 5.51 & 18 & 2.28 & 2.78 & 2.39 & 3.33 \\
\hline 6 & 6.45 & 21 & 2.14 & 2.81 & 3.05 & 5.67 \\
\hline All Ages & 4.34 & 119 & 1.45 & 1.82 & 1.52 & 2.29 \\
\hline \multicolumn{7}{|c|}{ GIRLS } \\
\hline 3 & 3.45 & 36 & $\begin{array}{l}0.46 \\
0.92\end{array}$ & 0.54 & 0.32 & 0.39 \\
\hline 4 & 4.50 & 16 & 1.50 & $\begin{array}{l}0.97 \\
1.88\end{array}$ & $\begin{array}{l}1.11 \\
2.00\end{array}$ & $\begin{array}{l}1.36 \\
2.44\end{array}$ \\
\hline 5 & 5.55 & 30 & 1.73 & 2.00 & 2.00 & 2.93 \\
\hline 6 & 6.41 & 17 & 0.94 & 1.06 & 3.29 & 5.35 \\
\hline All Ages & 4.26 & 127 & 1.09 & 1.24 & 1.55 & 2.19 \\
\hline \multicolumn{7}{|c|}{ BOYS AND GIRLS COMBINED } \\
\hline All Ages & 4.30 & 246 & 1.26 & 1.52 & 1.54 & 2.24 \\
\hline
\end{tabular}




\section{TABLE 5}

Mean Numbers of Decayed Deciduous Anterior and Posterior Teeth and Tooth Surfaces in Children with Anterior Hypoplasia by Sex, Ages Combined, Guatemala, 1973

\begin{tabular}{|c|c|c|c|c|c|c|}
\hline \multirow[b]{2}{*}{$\begin{array}{c}\text { Sex } \\
\text { Group }\end{array}$} & \multirow{2}{*}{$\begin{array}{l}\text { Mean } \\
\text { Age } \\
(\mathrm{Yr})\end{array}$} & \multirow[b]{2}{*}{$\mathrm{N}$} & \multicolumn{2}{|c|}{ Anterior Segment } & \multicolumn{2}{|c|}{ Posterior Segment } \\
\hline & & & $\begin{array}{c}\begin{array}{c}\text { Mean } \\
\text { deft }\end{array} \\
\end{array}$ & $\begin{array}{c}\text { Mean } \\
\text { defs }\end{array}$ & $\begin{array}{c}\text { Mean } \\
\text { deft }\end{array}$ & $\begin{array}{l}\text { Mean } \\
\text { defs }\end{array}$ \\
\hline Boys & 4.28 & 56 & 3.23 & 4.93 & 3.84 & 7.16 \\
\hline Girls & 4.29 & 57 & 2.68 & 3.98 & 3.03 & 5.28 \\
\hline Both Sexes & 4.29 & 113 & 2.95 & 4.45 & 3.43 & 6.21 \\
\hline
\end{tabular}

enced in the grossly hypoplastic anterior teeth.

\section{Discussion}

Children with anterior LEH would be expected to have a greater caries experience in the maxillary anterior teeth. ${ }^{3,4,8} \mathrm{~A}$ significantly greater caries experience in the posterior teeth of children with anterior LEH, however, has not been reported previously. Since deciduous molars rarely manifest linear hypoplasia, the mechanisms that result in a greater caries experience for these teeth are not known. Some children without anterior LEH had linear hypocalcified lines that corresponded to the areas in the maxillary incisors where linear hypoplasia is usually observed. In these cases, there was no observable discontinuity in the normal contour of the enamel surface. Perhaps the posterior teeth of children with anterior LEH are affected similarly, resulting in hypocalcification or hypomaturation in areas of these teeth that are not readily apparent by clinical observation. Although there is considerable variation in children in terms of the relative timing of enamel calcification of individual teeth, the molars probably have completed little more than cusp formation at the time hypoplasia develops in the anterior teeth. These observations suggest that enamel laid down in both the anterior and posterior teeth subsequent to ameloblastic dysfunction in the anterior teeth may be more susceptible to decalcification. Clinically, the progression of anterior caries from the hypoplastic defect is usually toward the cervical area of the tooth, the crown portion developed subsequent to the formation of hypoplasia.

To date, it has usually been assumed that the progression of caries to the cervical area of the tooth was the result of a greater accumulation of plaque as compared to the more incisal portion of the crown. However, teeth have not been analyzed to determine the hypocalcification status for the portions of the crown that develop both before and subsequent to the hypoplastic defect. Likewise, salivary glandular development or dysfunction in children with LEH also has not been studied and might merit further investigation.

For children with LEH, Table 1 shows that 6-year olds had fewer mean numbers of def molar teeth and surfaces than 5-year-old children. Caries superimposed over the hypoplastic lesions becomes more extensive with advancing age. Thus, eliminating from the hypoplasia category a greater number of children who had decay in the maxillary incisors, to the extent that hypoplasia was not possible to determine (NPD), probably resulted in the ascertainment of a lower caries experience in the deciduous molars than was actually the case. Variability resulting from the small numbers at each age interval also may have resulted in the reversal for 6-year olds,

Although other associations with LEH might bear investigation, LEH has been reported only in children of undernourished populations, and hence it is not unreasonable to assume a nutritional association. In a study of children recovering from third-degree malnutrition, Sweeney, Saffirfi and de Leon ${ }^{4}$ reported that $73 \%$ had anterior LEH. Sweeney et $a l^{6}$ reported a significantly greater prevalence among Guatemalan children with infection during the first 35 days of postnatal development. The hypoplasia also has been observed among Apache Indian children ${ }^{8}$ who made up a population in which acute diarneal disease was common. ${ }^{9}$ Thus, acute diarrheal disease and its relation to nutritional status would seem to merit further investigations as a factor predisposing children of undernourished populations to a significantly greater caries attack rate.

The findings of this study suggest that the synergistic mechanisms of undernutrition and 
infection, which are thought to be responsible for the occurrence of $\mathrm{LEH}$ in the anterior teeth, also may predispose clinically norma! appearing deciduous molars to a significantly greater caries attack rate. Increased caries susceptibility of the deciduous molars in children with LEH seems to be as great as that observed in the anterior teeth. The caries experience in the molars of children without anterior LEH seems to be similar to that reported for U.S. white children.

As an alternate hypothesis, one might suggest that hypoplastic anterior teeth may facilitate the establishment of cariogenic bacteria in the entire mouth. However, this hypothesis seems more unlikely in view of observations indicating that the caries attack in first permanent molars was the same as that observed in U.S. white children. ${ }^{13}$

\section{Conclusions}

A study of anterior $\mathrm{LEH}$ in relation to dental caries experience in the deciduous dentition of rural Guatemalan children two through seven years of age indicated that children with anterior LEH had greater mean numbers of decayed deciduous molars than children without anterior LEH for each oneyear age group comparison.

The percentage of children with cariesfree deciduous molars was significantly lower in the group with anterior LEH versus the group without LEH.

In children without anterior LEH, caries in the deciduous molars was about the same as in US white preschool children.

In comparison to children without anterior LEH, children with LEH had a percentage increase in caries experience in the posterior dentition that was similar to the percentage increase in the anterior dentition. This finding suggests that the synergistic mechanisms of undernutrition and infection, which may underlie the occurrence of anterior LEH, also may predispose clinically normal appearing posterior teeth to an excessive caries attack equal to that observed in the grossly hypoplastic anterior tecth.

\section{References}

1. Jelliffe, D.B., and Jelitffe, E.F.P.: Linear Enamel Hypoplasia of Deciduous In- cisor Teeth in Malnourished Children, $A m$ J Clin Nutr 24:893, 1971.

2. Jones, M.R.; Larson, N.P.; and Prighard, G.P.: Dental Disease in Hawaii-I. Odontoclasia: A Clinically Unrecognized Form of Tooth Decay in the Pre-School Child of Honolulu, Dent Cosmos 72:439-450, 1930.

3. Mayer, J., and Baume, L.J.: Pathologie de la melanodontie infantile, de l'odontoclasie et de la carie circulaire, Rev Suisse Odontol $76: 48-92,1966$.

4. SWeEney, E.A.; SAfFir, A.J.; and de Leon, R.: Linear Hypoplasia of Deciduous Incisor Teeth in Malnourished Children, Am J Clin Nutr 24:29-31, 1971.

5. Sarimshaw, N.S.; TAYlor, C.E.; and GorDON, J.E.: Interactions of Nutrition and Infection, in: World Health Organization Monograph No. 57, Geneva: WHO, 1968.

6. Sweeney, E.A.; Cabrera, J.; Urrutia, J.; and Mata, L.: Factors Associated with Linear Hypoplasia of Human Deciduous Incisors, J Dent Res 48:1275-1279, 1969.

7. Infante, P.F., and Gillespie, G.M.: An Epidemiologic Study of Linear Enamel Hypoplasia of Deciduous Anterior Teeth in Guatemalan Children, Arch Oral Biol 19: 1055-1061, 1974.

8: InfFante, P.F.: Enamel Hypoplasia in Apache Indian Children, Ecol Food Nutr 3: 155-156, 1974.

9. Woodward, W.E.; HirsGhHORN, N.; SAGK, R.B.; Cash, R.A.; Brownlee, I.; Chickadonz, G.H.; Evans, L.K.; Sheperd, R.H.; and Woodward, R.C.: Acute Diarrhea on an Apache Indian Reservation, Am J Epidemiol 99:281-290, 1974.

10. InFante, P.F.; OWen, G.M.; and Russell, A.L.: Dental Caries in Preschool Apache Indian Children, J Dent Res 54:915, 1975.

11. Russell, A.L.: Dental Caries and Nutrition in Lebanon, $J$ Dent Res 45:957-963, 1966.

12. Russell, A.L.; Leatherwood, E.C.; van Hien, L.; and van Reen, R.: Dental Caries and Nutrition in South Vietnam, J Dent Res 44:102-111, 1965.

13. Infante, P.F., and Gillespie, G.M.: Dental Caries Experience in the Deciduous Dentition of Rural Guatamalan Children Ages 6 Months to 7 Years, J Dent Res 55 : 951-957, 1976.

14. Infante, P.F., and Russell, A.L.: An Epidemiologic Study of Dental Caries in Preschool Children in the United States by Race and Socioeconomic Level, I Dent Res 53: 393-396, 1974. 